International Archives of the Photogrammetry, Remote Sensing and Spatial Information Sciences,

Volume XL-1/W1, ISPRS Hannover Workshop 2013, 21 - 24 May 2013, Hannover, Germany

\title{
APPLICABILITY ANALYSIS OF ULTRA-LIGHT UAV FOR FLOODING SITE SURVEY IN SOUTH KOREA
}

\author{
Insu. Lee ${ }^{\mathrm{a},}$, , Jihun. Kang ${ }^{\mathrm{b}}$, Gabsoo. Seo ${ }^{\mathrm{c}}$ \\ ${ }^{a}$ Spatial Information Research Institute (SIRI),Korea Cadastral Survey Corp., Seoul, Republic of Korea \\ islee0614@naver.com \\ ${ }^{\mathrm{b}}$ Spatial Information Research Institute (SIRI),Korea Cadastral Survey Corp., Seoul, Republic of Korea \\ kangdaejang@naver.com \\ ${ }^{\mathrm{c}}$ Spatial Information Research Institute (SIRI),Korea Cadastral Survey Corp., Seoul, Republic of Korea \\ gsseo@1x.or.kr
}

Commission VI, WG VI/4

KEY WORDS: UAV (Unmanned Aerial Vehicle), Flood Mapping, Ground survey, Cadastral

\begin{abstract}
:
Recently, UAV (Unmanned Aerial Vehicle) is used in a variety of fields such as the military service, fire prevention, traffic supervision, mapping, and etc. The increased demand for UAVs is typically attributed to the low manufacturing and operational costs, flexibility of the platforms to accommodate the consumer's particular needs and the elimination of the risk to pilots' lives in difficult missions. But, in South Korea, UAV might be first introduced to military service, and is still in its infancy, just being available for construction site monitoring, landscape photographing, spraying agricultural chemicals, broadcasting fields.

This study presents the background and the aim of flood mapping, and presents the possibility analysis of how to use UAV effectively for flooding area. And author tries to overlap UAV image with the flooding area trace surveyed by ground surveys. As a result, it is expected that UAV photogrammetry will contributes to investigating the flooded area by providing images, which is describing the flooded area in near real-time and also making a decision like paying compensation.
\end{abstract}

\section{INTRODCUTION}

UAV (Unmanned Aerial Vehicles) system is the state of art photogrammetry system which are using in documenting the cultural heritage, investigating the hazard area, monitoring the construction sites, etc. in domestic. But, ultra-light UAV is not so mature in South Korea.

In the domestic, Ultra-light UAV case study is as followed; National Emergency Management Agency(2007) dealt with a low altitude UAV image correction and improvement study, image processing technology development and resolution analysis of low altitude image information in the project of estimation module development of damaged area using geospatial imagery information. Jung et al (2010) proposes a method that shall rapidly 3D information of the fast and frequently changing city areas by using the images taken by the UAV photogrammetric method, and to develop the process of the acquired data. Jeong et al (2012) studied the building up a crop information delivery system using a multi-copter equipped with 8propellers. Kim et al (2010) introduces the application and its model of UAV to prepare, response and restoration from natural disaster to make use of the UAV. And Lee et al (2012) tested UAV for some cadastral applications, which are based on imagery.

On the outside, Cunningham et al (2011) presents the various sensors and payloads for mapping, and share his experience and optical systems for creating some of the first cadastral surveys in rural Alaska. Lambers et al (2007) describes the combined use of a mini helicopter and a terrestrial laser scanner, both equipped with a camera, allowed a fast yet accurate recording of the site and its stone architecture. And Khairul Nizam Tahar et al (2011) utilizes UAV system for large scale mapping. Also UAV is used in the diverse fields such as crop monitoring(Hunt, 2010), cadastre(Manyoky et al., 2011), vegetation monitoring (Sugiura, et al., 2005), classification of hyperspectral UAV imagery(Laliberte, et al., 2007) and precision farming (Reidelstuerz, et al., 2007).

In this study, main goal is presenting the possibility analysis of how to use UAV effectively for flooding area. To do this, UAV photogrammetry has been done, and author tries to overlap UAV images with cadastral surveying results, topographic map and cadastral map.

\section{FLOOD MAPPING}

The flood map is very useful for preventing and restoring a variety of hazard. Flood map presents the trace of flood caused by the typhoon, heavy rail, tsunami, etc. In South Korea, flood mapping project has been performed and surveyed on a national scale by Korea Cadastral Survey Corp (KCSC), required by National Emergency Management Agency (NEMA), Ministry of Security and Public Administration, Republic of Korea.

\footnotetext{
* Corresponding author.
} 
KCSC branches have been spread all over the nation, so it is very effective to get flooded area's positions and area. Also, surveying teams of each KCSC branches have surveyed the flooded region's area $\left(\mathrm{m}^{2}\right)$ and related information such as rainfall, disaster prevention facilities, etc.

In April 23, 2012, the MOU between NEMA and KCSC is embedded in the contract for preventing and managing the natural hazard together.

The importance of flood map is being proven when planning the some land development projects, administrative plan and the hazard prevention projects. However, there were no regulations such as its provider, methods and procedures so far, recently, NEMA said, according to the enforcement ordinance of countermeasures against Natural Disasters Act, a local government head should submit the flood map to the head of NMEA within 6 months after the occurrence of flooding. Flood mapping project comprises of analyzing why it is happened and what is needed to protect and restore it. This flood mapping project will much contribute to prevent the disaster technologically from the point of NEMA.

\section{INVESTIGATION OF FLOODING AREA}

\subsection{Overview}

This disaster was caused by typhoon "SANBA", Sept. 14 17, 2012(4days), resulted in the overflow of river, local inhabitants said. And then, the low lying grounds were submerged. The flooded area is located at Myeongji-dong, Gangseo-gu, Busan, South Korea (Fig. 1). The period for investigation is Sept.26, 2012 Oct. 31 (36 days), and 3 people were involved. And these sites were flooded for 59 hours.

Full damaged area is about 12 parcels $\left(2349 \mathrm{~m}^{2}\right)$, and partly damaged areas is 21 parcels $\left(6820 \mathrm{~m}^{2}\right)$. Area of a damaged private property is $1984 \mathrm{~m}^{2}$. But, no people were damaged.

And height of flooding is about $1.6 \mathrm{~m}$, and its depth, $0.3 \sim 0.8 \mathrm{~m}$ its mean $0.46 \mathrm{~m}$. Now this site is being utilized as a residential section and a river area.

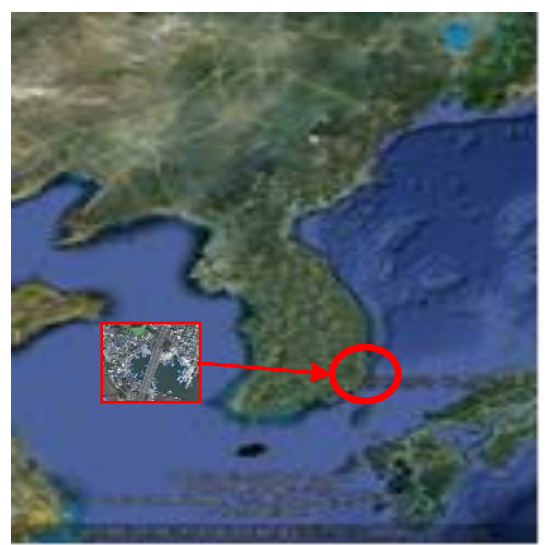

Figure 1. Test area (courtesy of Google)

The main investigation items of the flooding area trace is as following: range of flooded area, flood duration, height of flooding depth of flooding mark, and breakdown point of river bank, and flooding shape (overflow of river, flooding, overflow of river and flooding), hidden provokers for damages, and the main damage contents should be investigated.

Topographic map (scale $1 / 25,000,1 / 5,000,1 / 1,000$ ) and cadastral map is used to investigate the status and the data for the damaged area roughly. The person in charge visits the administrative offices and collects the damage related information. Next, the flooding area trace is displayed on topographic map sketchy, after then the person in charge visit the damaged site, listen to the damaged status from the related residents, then, and investigate the main contents of the flooding area trace and that of the building and the main terrain features (See. Fig.2)

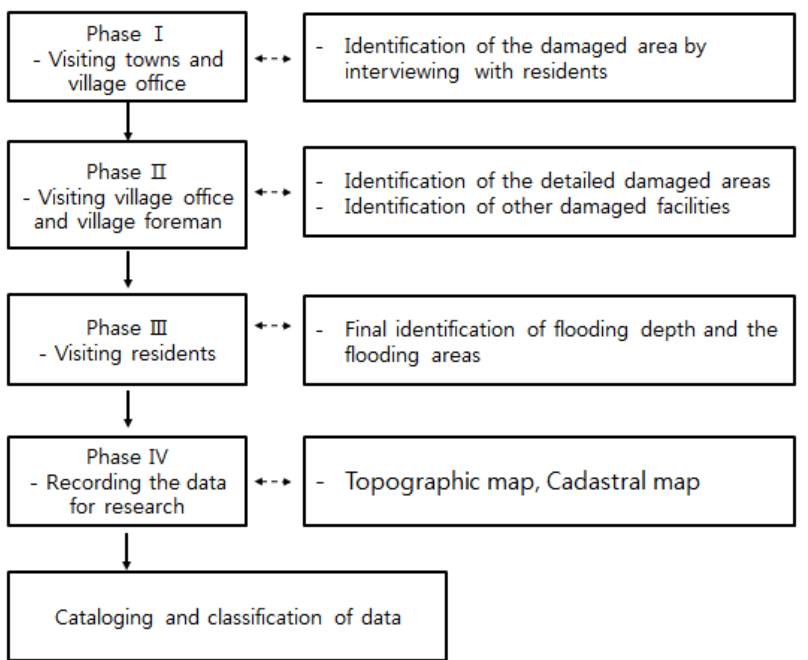

Figure 2. Flowchart of the flooding area investigation

Figure 3 describes the inner part of flooded houes. Through this, it was proven that the flood depth is high enough the wall and the floor of house is too wet.

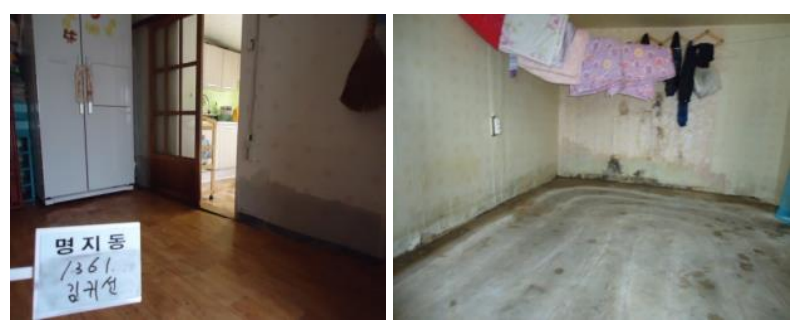

Figure 3. Flooded house' wall and floor

\subsection{UAV photogrammetry}

In this study, LX-UAV I is manufactured by Spatial Research Institute, KCSC with help of an outside expert. The main components of the LX-UAV I are a remote control, the flight control software and its body. Equipped with six rotors, the LXUAV I system possesses a maximum payload of $7 \mathrm{~kg}$. Other important elements of the LX-UAV I are one GPS (Global Positioning System), one linear accelerometer (LIS, and two Gyros (e.g. IDG-500, IDZ-500).

The detailed specification of hexacopter is prescribed in Table 1 . In particular, this LX-UAV I is just prototype model for cadastral applications. Hexacopter has 6 blades where 3 blades rotate clockwise direction and 3 blades counter-clockwise. Figure 4 shows an example of UAV (hexacopter) and a digital camera. 


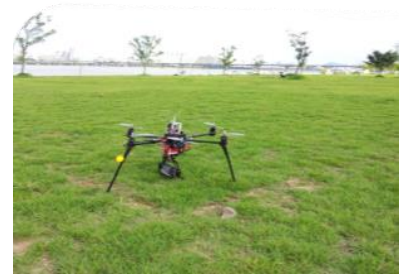

(a)

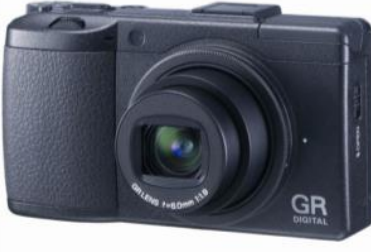

(b)
Figure 4. Hexacopter (a) and Digital camera (b)

For UAV flight, two persons were required for data acquisition, a hexacopter pilot and a safety man. A hexacopter pilot selected the optimal positions for the UAV for take-off. And the other man took safety measures in case of the emergency because the test site was surrounded with sea and there were many people working in small harbor. In this kind of worse environment, a trained pilot is required for safety reason.

\begin{tabular}{|c|c|c|c|}
\hline Climb rate & $\begin{array}{l}\text { Altitude hold } \\
- \text { Max } 6 \mathrm{~m} / \mathrm{s} \\
\text { Normal } \\
- \text { up to } 10 \mathrm{~m} / \mathrm{s}\end{array}$ & Wind tolerance & $3 \mathrm{~m} / \mathrm{s}$ \\
\hline Cruising speed & Up to $5 \mathrm{~m} / \mathrm{s}$ & Flight radius & Up to $1000 \mathrm{~m}$ on RC \\
\hline $\begin{array}{c}\text { Maximum } \\
\text { take-off weight }\end{array}$ & $\begin{array}{c}7 \mathrm{~kg} \\
\text { (incl. body) }\end{array}$ & $\begin{array}{c}\text { Operation } \\
\text { altitude }\end{array}$ & Up to $1000 \mathrm{~m}$ on RC \\
\hline Empty weight & $\begin{array}{c}3.5 \mathrm{~kg} \\
\text { (incl. battery) }\end{array}$ & $\begin{array}{c}\text { Flight time } \\
\text { Up to } 5 \text { minutes }\end{array}$ \\
\hline Temperature & $-10 \sim 50{ }^{\circ} \mathrm{C}$ & $\begin{array}{c}\text { Hovering } \\
\text { Accuracy } \\
\text { (Altitude Hold) } \\
\text { (GPS Hold) }\end{array}$ & $\begin{array}{c}\text { Vertical } \pm 1 \mathrm{~m} \\
\text { Horizontal } \pm 5 \mathrm{~m}\end{array}$ \\
\hline $\begin{array}{c}\text { Max Angle } / \\
\text { Max Yaw } \\
\text { Angular Velocity }\end{array}$ & $60^{\circ} / 150^{\circ}$ & Dimension & $900 \mathrm{~cm} \times 900 \mathrm{~cm}$ \\
\hline
\end{tabular}

Table 1. Hexacopter specification

Table 2 shows the digital camera specification in more details. In this study, Ricoh GD D IV digital camera has been used in acquiring images. The Ricoh GD D IV is attached at the bottom of hexacopter to capture aerial images during flight operation.

\begin{tabular}{|c|l|l|}
\hline \multicolumn{2}{|c|}{ Item } & \multicolumn{1}{c|}{ Specifications } \\
\hline \multicolumn{2}{|c|}{ Image Sensor } & $\begin{array}{l}\text { 1/1.7-inch CCD } \\
\text { (approx.10.40 million pixels) }\end{array}$ \\
\hline \multirow{2}{*}{ Lens } & Focal length & $\mathrm{f}=6.0 \mathrm{~mm}$ \\
\cline { 2 - 3 } & $\begin{array}{l}\text { Shooting } \\
\text { distance }\end{array}$ & Approx. 30 cm \\
\hline $\begin{array}{l}\text { Digital Zoom } \\
\text { Magnification }\end{array}$ & $\begin{array}{l}\text { Digital } \\
\text { Zoom }\end{array}$ & Approx. 4.0x \\
\hline External Dimensions & $\begin{array}{l}108.6 \mathrm{~mm}(\mathrm{~W}) \text { x 59.8 mm (H) } \\
\text { x 32.5 mm (D) }\end{array}$ \\
\hline \multicolumn{2}{|l|}{ Weight } & $\begin{array}{l}\text { Approx. 219g (incl. battery } \\
\text { and SD memory card) }\end{array}$ \\
\hline
\end{tabular}

Table 2. Camera Major Specification (Ricoh, 2012)

The pilot manually lifted the UAV into the air. And the UAV began its flying about 6 minute's path over the small harbour sky. At this moment, it is very difficult to handle UAV because of a turbulent wind although a pilot is trained for a long time.

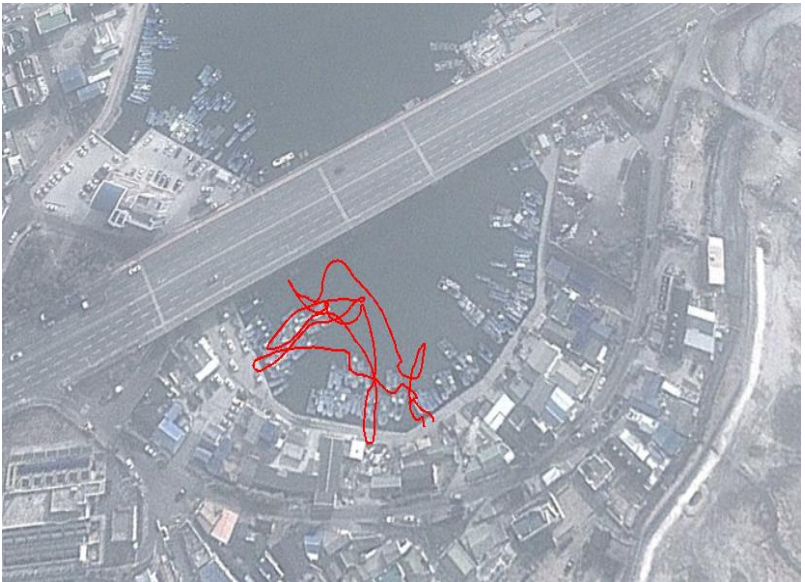

Figure 5. GPS logging

As mentioned in advance, the strong wind has effect on this irregular UAV flight path (See. Fig.5). The photograph has been taken over about $300 \mathrm{~m}$ altitude; its foot print about $200 \mathrm{~m}$ $\times 150 \mathrm{~m}$. Figure 6 shows the panoramic view of harbour. This was raw image, not ortho-rectified.

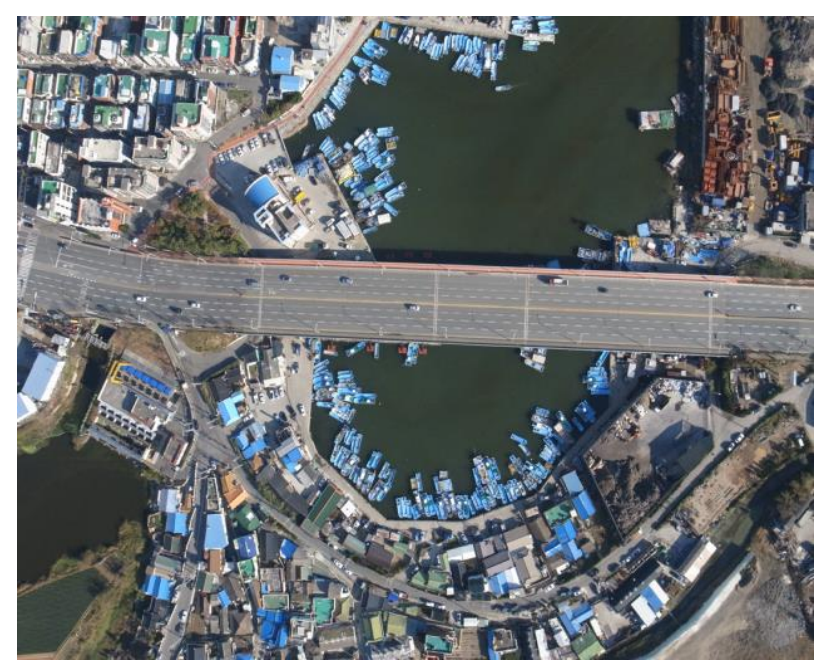

Figure 6. UAV raw images

\subsection{Ground surveying}

The civil servant working in local government requests the ground surveying to the branches of KCSC. KCSC surveyors are doing the detailed cadastral surveying with tacheometer as soon as the local government asks for. Figure 7 and 8 describes the trace of the flooding area, and it was overlapped with cadastral map and topographic map (scale 1/3000), respectively.

And the final map and the report are sent to the local government office. The final results also are uploaded to the dedicated the system for the flooding area management, which is owned by KCSC. Through this system, the civil servant in charge and the person working at NMEA could grasp the various data for flooding area trace anywhere. 


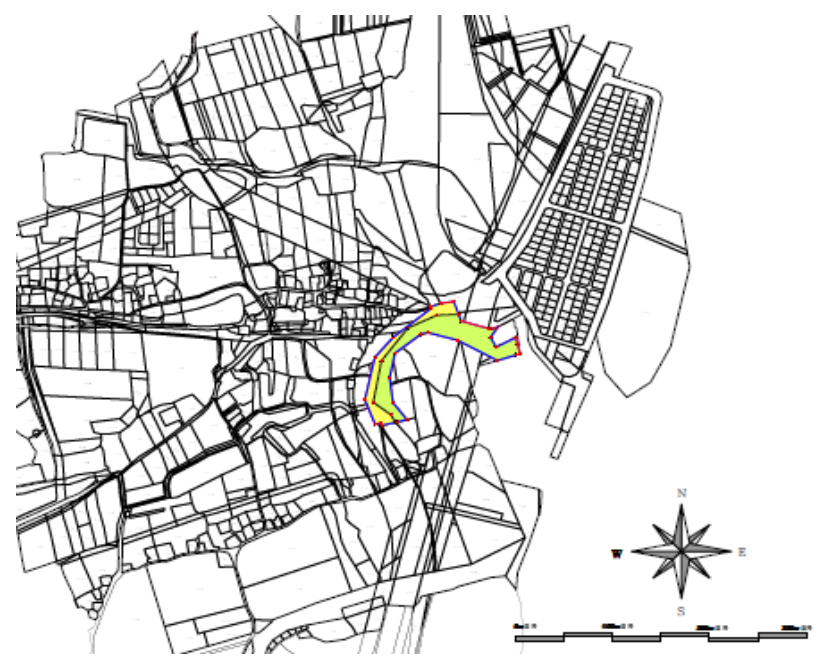

Figure 7. Overlap of Cadastral Map with flooding area map

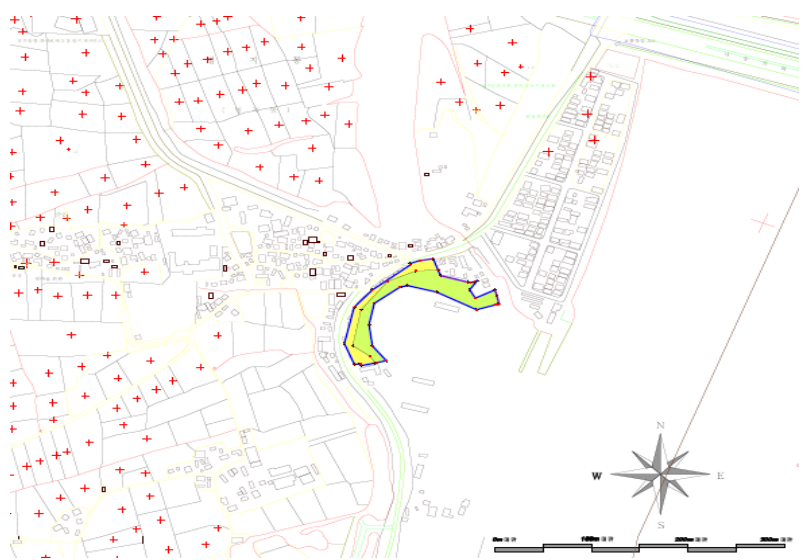

Figure 8. Overlap of topographic map with flooding area map

\subsection{Overlap of UAV photographs with flooding area map}

Figure 9 shows the overlap of UAV photographs with the flooding area trace. With UAV photographs, the public servant in charge would easily confirm the damaged status for flooding area and also this will contribute to paying compensation for flooding area.

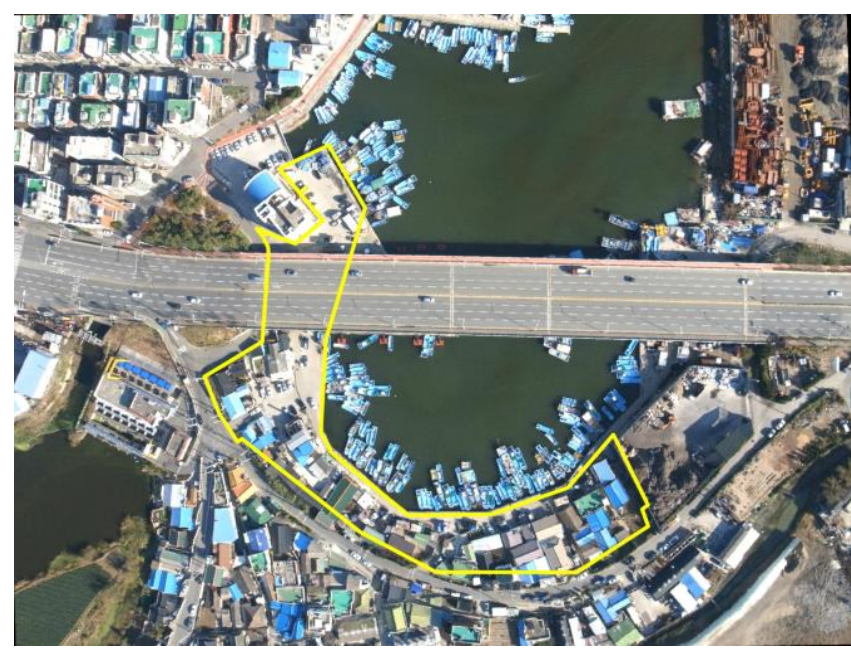

Figure 9. Overlap of UAV image with surveying results

\section{CONCLUDING REMARKS}

This study presents the applicability of UAV usage in flooding mapping instead of ground surveying. And author review the UAV photogrammetric methods in terms of effectiveness and cost-saving, comparing with ground surveying in mapping the flooding area. But, the UAV images were raw, not perfectly processed enough to apply for flooding mapping at the time of writing. Therefore, author tries to just overlap the UAV image with the flooding area measured by ground surveying, and also, put the flooding area on the cadastral map and topographic map. With this, it is expected that UAV image could contribute to making a decision for pay compensation for the flooding area. But there are many things such as the taking the geo-referencing, safety problem, the demarcation of flooding area, the interpretation of the related law, etc. for UAV to be applied for mapping the flooding area,

\section{REFERENCES}

Cunningham, K., Walker, G., Stahlke, E. and Wilson, R, 2012, Cadastral Audit And Assessments using Unmanned Aerial Systems, International Archives of the Photogrammetry, Remote Sensing and Spatial Information Sciences, Vol. XXXVIII-1/C22 UAV-g 2011, Conference on Unmanned Aerial Vehicle in Geomatics, Zurich, Switzerland.

Hunt, E.R., Jr., Hively, W.D., Fujikawa, S. J., Linden, D.S., Daughtry, C.S.T., and McCarty, G.W, 2010. Acquisition of NIR-Green-Blue Digital photographs Evaluation of digital photography from from Unmanned Aircraft for Crop monitoring. Remote Sens. 2010, 2, 290-305.

Jeong, Seungtaek, Ko, Jonghan, Yeom, Jong-Min, and Kim, Han-Yong, 2012, Crop Information Delivery System using and Unmanned Aerial Vehicle, 2012 Proceedings of KAGIS Fall Conference, November 8 10, Jeju University, Jeju, pp. 296-297.

Jung , Sung Heuk, Lim, Hyeong Min, Lee, Jae Kee, 2010, Acquision of 3D spatial information using UAV photogrammetric method, Korean Journal of Geomatics, 28(1), pp.161-168.

Kim, Min Gyu, Jung, Gap Yong, Kim, Jong Bae, Yun, Hee Cheon, Applicability Analysis of UAV for Storm and Flood Monitoring, Korean Journal of Geomatics, 28(6), pp. 655-662.

Khairul Nizam Tahar., Anuar Ahmad.,,Wan Abdul Aziz Wan Mohd Akib \& Wani Sofia Udin., UNMANNED AERIAL VEHICLE TECHNOLOGY FOR LARGE SCALE MAPPING, ISG \& ISPRS 2011, Sept. 27-29, 2011 - Shah Alam, MALAYSIA.

Laliberte, A., S., Winters, C. and Rango, A., 2007. Acquisition, orthorectification, and classification of hyperspatial UAV imagery, In: Fourth Annual Symposium: Research Insights in Semiarid Scosystems, RISE, University of Arizona, Tucson.

Lambers, K., Eisenbeiss, H., Sauerbier, M., Kupferschmidt, D.,Gaisecker, Th., Sotoodeh, S., Hanusch, Th., 2007. Combining photogrammetry and laser scanning for the recording and modelling of the late intermediate period site of Pinchango Alto, Palpa, Peru, Journal of Archaeological Science 34(10), 1702-1712, Amsterdam. 
Lee, Insu, Kim, Sujeoung. and Seo, Gabsoo, 2012, Development of Imagery-based cadastral map and its application - UAV project in cadastre, Report 2012-04, Spatial Information Research Institute, KCSC.

Manyoky, M., Theiler, P,, Steudler, D. and Eisenbeiss, H, 2011, Unmanned Aerial Vehicle in Cadastral Applications, International Archives of the Photogrammetry, Remote Sensing and Spatial Information Sciences, Vol. XXXVIII-1/C22 UAV-g 2011, Conference on Unmanned Aerial Vehicle in Geomatics, Zurich, Switzerland.

National Emergency Management Agency, 2007, Development of damage estimation module using geospatial imagery information.

Reidelstuerz, P., Link, J., Graeff, S. and Claupein, W., 2007. UAV(unmanned aerial vehicles) für Präzisionslandwirtschaft. 13. Workshop Computer-Bildanalyse in der Landwirtschaft \& 4. Workshop Precision Farming, In: Bornimer Agrartechnische Berichte, 61, 75-84.

Ricoh, 2012, http://www.ricoh.com.

Shin, Chulhuk, 2006, Mapping the flooded area by the GIS, Master thesis, Graduate school, Kangwon National University, Chuncheon-si, Republic of Korea.

Sugiura, R., Noguchi, N. and Ishii, K., 2005. Remote-sensing Technology for Vegetation Monitoring using an Unmanned Helicopter, In: Biosystems Engineering, 90, 4, 369-379. 